\title{
Prevalence of Brain Microbleeds in Alzheimer Disease: A Systematic Review and Meta-Analysis on the Influence of Neuroimaging Techniques
}

\author{
(D)A.A. Sepehry, (DD. Lang, (D) G.-Y. Hsiung, and (D) A. Rauscher
}

\begin{abstract}
BACKGROUND AND PURPOSE: The literature on the prevalence of Alzheimer disease-associated cerebral microbleeds assessed with MR imaging shows considerable heterogeneity in terms of imaging techniques and parameters. Our aim was to perform a meta-analysis of the role of imaging techniques, including image acquisition, field strength and scanner type, and clinical and demographic factors on the reported prevalence of microbleeds in Alzheimer disease.
\end{abstract}

MATERIALS AND METHODS: The prevalence of microbleeds was examined with respect to a priori-selected moderating variables via meta-analytic tools of literature reports.

RESULTS: Fourteen unique studies providing 15 microbleed prevalence rates met the selection criteria for inclusion. The aggregate prevalence of microbleeds was $24 \%(95 \% \mathrm{Cl}, 19 \%-28 \%)$. Scan (SWI $=40 \%$, gradient echo $=18 \%, \mathrm{EPI}=19 \%$ ) and field strength (slope $=0.39$; standard error $=15, P<.01)$ influenced the prevalence of microbleeds. The associations between microbleeds and age, sex, and global cognitive status were not significant. After updating the literature, the aggregate prevalence remained in the $95 \% \mathrm{Cl}$ range.

CONCLUSIONS: Imaging technique and field strength are strongly associated with the prevalence of microbleeds over the global aggregate. Standardized imaging protocols for identification of microbleeds are recommended to minimize confounds.

ABBREVIATIONS: $\mathrm{AD}=$ Alzheimer disease; $\mathrm{ER}=$ event rate; $\mathrm{GRE}=$ gradient recalled-echo imaging; $\mathrm{MB}=$ microbleed; $\mathrm{MCI}=$ mild cognitive impairment; $\mathrm{STROBE}=$ STrengthening the Reporting of OBservational studies in Epidemiology

A growing number of studies have suggested that the presence of microbleeds (MBs) and the overall microbleed burden have prognostic significance for Alzheimer disease (AD). ${ }^{1,2}$ In $\mathrm{AD}, \mathrm{MBs}$ are thought to contribute to the pathophysiology of the illness, demonstrating a link between amyloid pathology and neurovascular change. ${ }^{3}$ Although still controversial, the impact of MBs on the progression of mild cognitive impairment (MCI) due to incipient $\mathrm{AD}$ and subsequent emergence of $\mathrm{AD}$ has been suggested. ${ }^{4}$ It is not clear whether MBs are consequences of $\mathrm{AD}$ or cerebral amyloid angiopathy, or just a bystander. Current data on the impact of MBs on global cognition have been equivocal, and

\footnotetext{
Received March 31, 2015; accepted after revision July 11.

From the Division of Neurology (A.A.S., G.-Y.H.), Department of Medicine; Departments of Paediatrics (A.A.S., A.R.) and Radiology (D.L.); University of British Columbia, Vancouver, British Columbia, Canada.

Please address correspondence to Amir A. Sepehry, MSc, PhD, University of British Columbia, University of British Columbia Hospital, Division of Neurology, 2211 Wesbrook Mall, Vancouver, BC, Canada; e-mail: sepehryaa@alumni.ubc.ca; @rauscherMRI, @asmetaanalysis

$\equiv$ Indicates article with supplemental on-line tables.

Indicates article with supplemental on-line photos.

http://dx.doi.org/10.3174/ajnr.A4525
}

most studies showed a minimal effect of MBs. ${ }^{5}$ The lack of effect has been associated with small sample size, insufficient $\mathrm{MB}$ counts to cause any cognitive change, or AD severity masking the subtle effect of MBs on neurocognitive functioning. ${ }^{6}$ Heterogeneous classifications and poor validation of both the presence and prevalence of MBs have further obscured potential relationships between neurocognitive functioning and MBs. ${ }^{7,8}$ With respect to subregional neuropathology, few studies have directly examined the effect of MBs on other markers of $\mathrm{AD}$ such as CSF-associated amyloid antibodies or hippocampal atrophy. ${ }^{8,9}$

A number of clinical human studies examining the prevalence of $\mathrm{MBs}$ in $\mathrm{AD}$ have been published since 2000. The most recent review on the prevalence of $\mathrm{MBs}$ in $\mathrm{AD}$ included 4 unique studies. ${ }^{3}$ Those studies reported heterogeneous samples of patients with $\mathrm{AD}$ with varying severity of cognitive impairment, age ranges, sex, study design, and other confounds. Reported prevalence rates ranging between $17 \%$ and $32 \%$ were described, likely due to considerable heterogeneity of imaging acquisition techniques and $\mathrm{MB}$ identification approaches.

In MR imaging, paramagnetic hemosiderin in MBs gives rise to local field inhomogeneities, which affect both the magnitude 


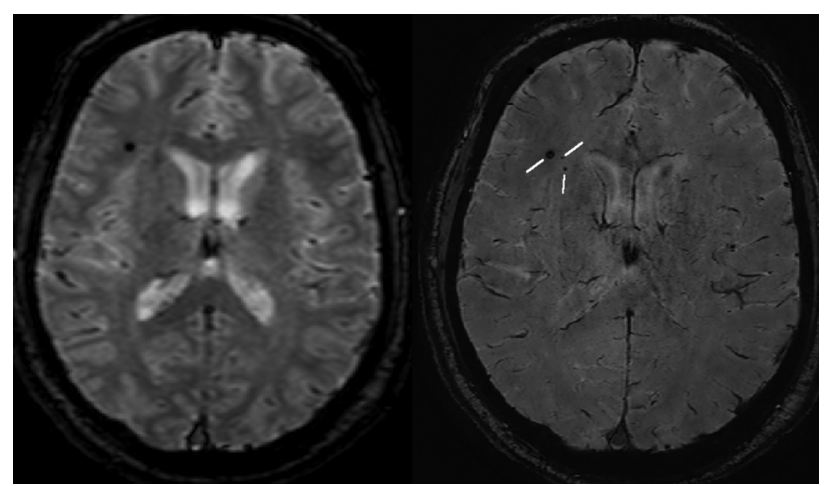

FIG 1. Gradient-echo MR imaging (left) and SWI (right) acquired in the same subject on a 3T Achieva (Philips Healthcare, Best, the Netherlands) with an 8-channel sensitivity encoding head coil and sensitivity encoding reconstruction of multichannel data. The gradient-echo scan shows 1 microhemorrhage when the more sensitive SWI scan detects 3 .

and the frequency of the MR imaging signal. Conventional gradient recalled-echo imaging (GRE) makes use of changes in the magnitude via loss in the $\mathrm{T} 2^{\star}$-weighted signal. Susceptibilityweighted imaging is a gradient-echo technique with high spatial resolution that generates images with improved sensitivity to MBs by also incorporating the MB effects on the MR signal frequency. ${ }^{10,11}$ Because SWI is a 3D sequence, it allows thin sections without intersection gaps. Typical spatial resolution of SWI is $0.5 \times 0.5 \times 2 \mathrm{~mm}$, whereas GRE sections are up to $5 \mathrm{~mm}$ thick with intersection gaps of up to $2 \mathrm{~mm}$. The improved spatial resolution allows SWI to capture small MBs, which may be missed with GRE. Imaging of MBs also benefits from increased magnetic field strength, which leads to a higher signal-to-noise ratio and makes the field inhomogeneities around MBs more pronounced, resulting in increased image contrast. The choices of both field strength and imaging technique have, therefore, a substantial influence on the visibility of small bleeds (Fig 1). With technical developments, the sensitivity of MR imaging to MBs has increased and the prevalence reported on previous reviews may have to be revised.

The purpose of this study was to conduct a meta-analysis of $\mathrm{MB}$ prevalence in $\mathrm{AD}$ that takes into account imaging, clinical, and demographic parameters.

\section{MATERIALS AND METHODS \\ Search Strategy}

MEDLINE and EMBASE were queried for a priori-defined key words with key terms and subject headings on September 9, 2014. The following were combined to yield our search outcome: SWI OR "susceptibility weighted imaging" OR "gradient echo imaging" OR "gradient echo MR imaging" OR "susceptibilityweighted MR imaging" OR MR imaging OR nuclear MR imaging AND Microbleed* OR microhemorrhage OR "petechial hemorrhage" OR hemosiderin OR "cerebral amyloid angiopathy" OR cerebral hemorrhage OR intracranial hemorrhages AND Alzheimer disease OR dementia OR Alzheimer*. Examining the reference list of review articles relevant to the study substantiated the search. The search of the literature was updated on May 11, 2015.

\section{Selection Criteria}

Two reviewing authors (A.A.S. and A.R.) examined all retrieved abstracts independently. Studies were retained when they reported both the diagnosis of $\mathrm{AD}$ and the prevalence of MBs. Articles were excluded if they were the following: 1) a case report, review, meta-analysis, letter, editorial, case-control or cross-sectional studies; 2) a treatment study; or 3) reported duplicate data on the following: 4) on postmortem brain; 5) atypical AD (eg, logopenic); 6) explicitly on familial AD type; or 7) included mixed groups (eg, AD with $\mathrm{MCI}$ ). The same method was applied to studies found by a hand search of reference lists of review articles. When disagreement occurred in study classification, further discussion was undertaken to reach concordance. Additionally, quantitative analysis of between-rater agreement was performed. The selection criteria were formulated to minimize statistical and sample heterogeneity.

\section{A Priori-Selected Moderating Variables}

The selected moderating variables were the following: imaging parameters including scanner type, field strength, and scan techniques; $\mathrm{MB}$ definition; age of patients with $\mathrm{AD}$ (total $\mathrm{AD}$ sample); global cognitive scores of the sample; sex; diagnosis of $\mathrm{AD}$ (possible or probable); study design; hemorrhage; infarct/lacuna; stroke; and the anatomic distribution of MBs. Due to the limited number of included studies and the large number of variables, exploratory single-variable meta-regressions were performed.

\section{Effect Size and Calculations}

Event rates (effect sizes) were generated by using the reported prevalence rate for MBs $(>1)$ in patients with $\mathrm{AD}$ for each study. Subsequently, an aggregate measure was computed by using the random-effects model that takes into account the sample size from each study. For categoric and continuous-type moderating variables, meta-regression or categoric analyses were performed. All the analyses and graphs were implemented by using Comprehensive Meta-Analysis (Version 2.0, https://www.meta-analysis. (om). ${ }^{12}$

Each study contributed 1 time to the aggregate event rate estimate, unless the authors provided different event rates for different techniques. For the study reporting field strengths of $1 \mathrm{~T}$ and $1.5 \mathrm{~T}$, the lower field strength was used. For studies reporting cognitive scores or mean age for patients with and without MBs, an aggregate mean and SD were calculated by using D-STAT ${ }^{13}$ and were subsequently used in the overall analyses. Comparison between the prevalence of MBs in patients with $\mathrm{AD}$ versus healthy controls and those with subjective cognitive impairment and other dementias was performed by using odd ratios. Examination of the effect of antiplatelet medication, the apolipoprotein E4 allele (presence and percentage reported), hypertension, and immunotherapy when possible was performed by using categoric and meta-regression analyses. For all analyses, the critical level of significance was set to $5 \%$. For all meta-regressions, secondary (aggregate) statistics were used. The reported prevalence (event rate) from each study was transformed to a log scale to allow both continuous and dichotomized moderating variables. For singlevariable meta-regressions, we regressed the moderating variable 


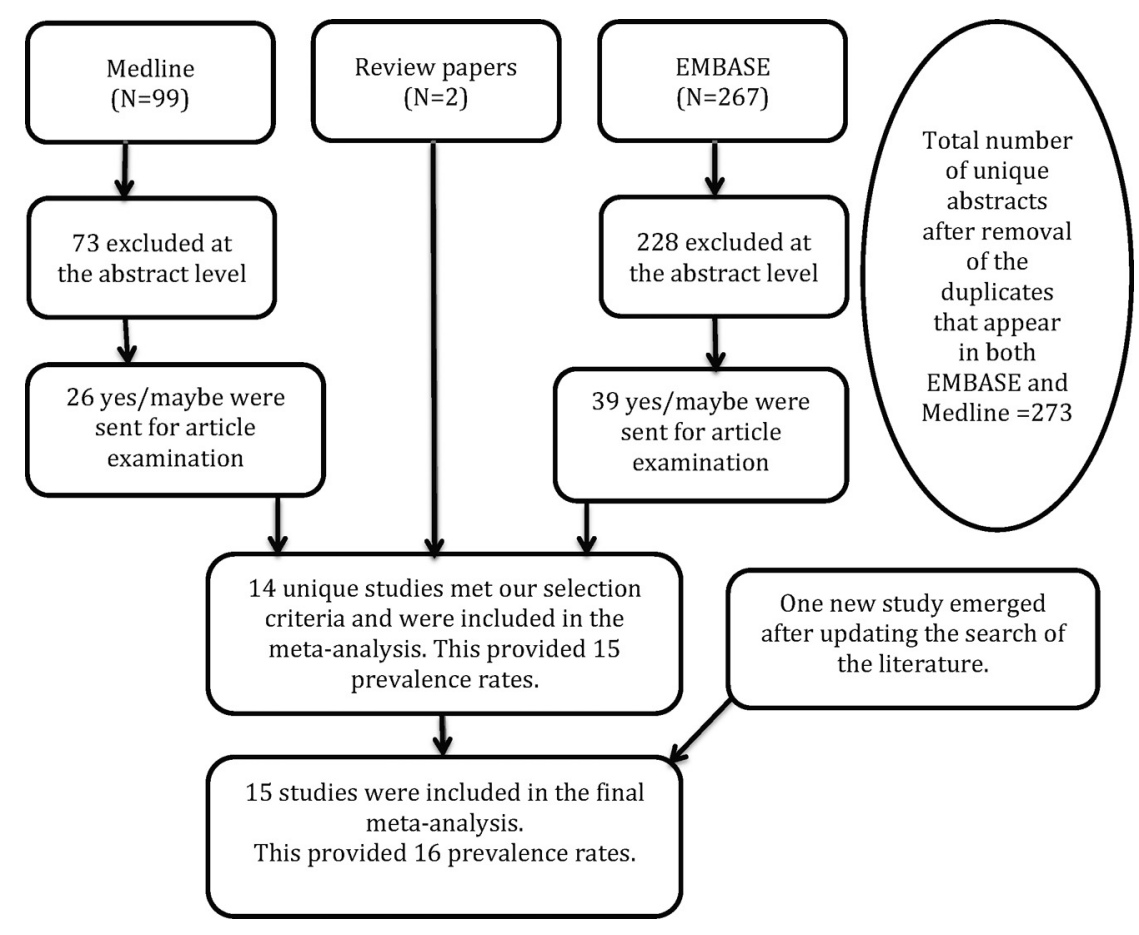

FIG 2. Flow diagram showing the progress of data collection.

on the prevalence rate. The $\mathrm{R}^{2}$ analog was used to report the explained magnitude of between-study variance.

\section{Quality Assessment}

The quality of the included studies was assessed according to STrengthening the Reporting of OBservational studies in Epidemiology (STROBE) guidelines. ${ }^{14}$ For reporting of the meta-analysis data, when applicable, reference has been made to Meta-analysis of Observational Studies in Epidemiology or the Preferred Reporting Items for Systematic Reviews and Meta-Analyses (PRISMA) statement. ${ }^{15,16}$

\section{Assessment of Bias}

For examination of publication bias, the funnel plot and the Begg and Mazumdar rank correlation test ${ }^{17}$ and the test of the intercept of Egger et $\mathrm{al}^{18}$ were used. A significant $P$ value for both Begg and Mazumdar and Egger test is indicative of possible bias.

\section{Heterogeneity}

Statistical heterogeneity was examined for global and subsequent moderating variables by using the Q-statistic and $\mathrm{I}^{2} .{ }^{19}$ To minimize the magnitude of bias resulting from selectively dropping studies to explain heterogeneity and to keep the maximum number of studies in the analyses, we assessed the heterogeneity by using multivariable meta-regressions (incremental or diagonal approach) when applicable. The incremental approach was used when variables could have been added, and the diagonal was used when there was colinearity among variables. The first category consisted of imaging parameters including field strength, scan technique, and scanner type. The second category included demographics and Mini-Mental State Examination score. The third category pertained to clinical variables, including the effect of MB location and definition, lacunae, stroke, hemorrhage, $\mathrm{AD}$ diagnosis, and risk factors. Subsequently, analyses were performed of the following: 1) prevalence for other dementias and control groups, 2) risk factors including apolipoprotein E4 carriers (heterozygote, homozygotes, or both) and percentage with hypertension, 3) publication date on the prevalence of MBs, and 4) analyses based on updated literature.

\section{RESULTS \\ Study Selection}

The search of electronic literature yielded 273 unique abstracts (99 from MEDLINE and 267 from EMBASE). Also, 2 studies $^{20,21}$ emerged from the search of review articles. From these, 73 studies from MEDLINE and 228 from EMBASE were excluded at abstract screening. The remaining 26 from MEDLINE and 39 from EMBASE were examined for data and selection criteria in more detail. At this stage, the interrater $\kappa$ agreement was at 0.87 . From MEDLINE/EMBASE and emerging studies, 14 published studies met selection criteria and had no overlap with any other included study. One study ${ }^{22}$ reported results from 2 techniques in the same cohort, resulting in 15 reported prevalence rates for the subsequent analyses (see Online Table 1 for excluded studies, and flow-diagram, Fig 2). Therefore, the final included number of studies was 15 (Table 1 and On-line Table 2).

\section{Demographic Data and Acquisition Platforms of the Included Studies}

The sample sizes ranged from 10 to 550 . For the studies reporting global cognition scores as assessed by the Mini-Mental State Examination, the values ranged from 17.9 to 26 . The mean age range was $67-79.5$ years; the percentage of male subjects was between $29 \%$ and $51 \%$. AD diagnoses were reported as probable $\mathrm{AD}$, a mix of probable and possible $\mathrm{AD}$ as per the 1984 criteria of McKhann et $\mathrm{al}^{23}$ and unspecified.

Scanners used were Signa 1.5T and Signa 3T (GE Healthcare, Milwaukee, Wisconsin); Intera 1.5T, Intera 3T, and Achieva 3T (Philips Healthcare, Best, the Netherlands); and 1T Impact, 1.5T Avanto, 1.5T Vision, 1.5T Sonata, and 3T Trio (Siemens, Erlangen, Germany). The field strengths were 1T, $1.5 \mathrm{~T}$, and $3 \mathrm{~T}$; the techniques used were $\mathrm{T} 2{ }^{\star}$-weighted gradient echo, echo-planar imaging, and SWI. Most studies reported on diffuse/global distribution of the MBs and explicitly considered MBs as round and $\leq 10 \mathrm{~mm}$.

\section{Prevalence Aggregate}

The global event rate (ER) estimate for at least $1 \mathrm{MB}$ included 583 cases from a sample of 2333 ( $\mathrm{ER}=0.24, n=15)$ and was heterogeneous $\left(\mathrm{I}^{2}=85.99\right)$. Both graphic (funnel plot) and quantita- 
Table 1: Neuroimaging parameters of the included studies

\begin{tabular}{|c|c|c|}
\hline Studies & Scanner/Technique/Field Strength & Gap/Raters \\
\hline Benedictus et al, $2013^{28}$ & GE Healthcare/EPI/3T & Unknown/1 neuroradiologist \\
\hline Cordonnier et al, $2006^{7}$ & Siemens/GRE/1T & 1.5/1 observer, type unknown \\
\hline Fukui et al, $2013^{21, a}$ & Unknown/GRE/1.5T & Unknown \\
\hline \multirow[t]{2}{*}{ Goos et al, $2011^{22, b}$} & Siemens/GRE/1.5 & $1.5 / 1$ rater, type unknown \\
\hline & Siemens/SWI/1.5T & NA/1 rater, type unknown \\
\hline Kester et al, $2014^{29, a}$ & GE Healthcare, Siemens/GRE/IT, 1.5T, and 3T & Unknown \\
\hline Kirsch et al, $2009^{4}$ & Siemens/SWI/1.5T & $\mathrm{NA} / 4$ readers +1 neuroradiologist \\
\hline Nagasawa et al, $2014^{20}$ & Unknown/GRE/1.5T & $0.5 / 2$ neurologists, 1 neuroradiologist \\
\hline Nagata et al, $2012^{40}$ & Unknown/EPI/1.5T & Unknown/unknown \\
\hline Nakata-Kudo et al, $2006^{41}$ & Philips/GRE/1.5T & 1/1 neurologist, 1 radiologist \\
\hline Park et al, $2013^{42}$ & Philips/GRE/3T & $2 / 2$ neurologists in consensus \\
\hline Qiu et al, $2010^{43}$ & GE Healthcare/EPI/1.5T & $\mathrm{NA} / 1$ neuroradiologist and subsequent raters \\
\hline Staekenborg et al, $2009^{44}$ & Siemens/GRE/IT & 1.5/unknown \\
\hline Uetani et al, $2013^{24}$ & Siemens/SWI/3T & $\mathrm{NA} / 2$ neuroradiologists in consensus \\
\hline van der Vlies et al, $2012^{45}$ & Siemens/GRE/IT or $1.5 \mathrm{~T}$ & 1/unknown \\
\hline Yates et al, $2014^{46}$ & Siemens/SWI/3T & $\mathrm{NA} / 2$ neuroradiologists in consensus \\
\hline Zonnefeld et al, $2014^{47}$ & GE Healthcare/SWI/3T & NA/1 of 2 neuroradiologists \\
\hline Postupdate & & \\
\hline Olazarán et al, $2014^{27}$ & GE Healthcare/EPI/3T & NR/neuroradiologist \\
\hline
\end{tabular}

Note:-NA indicates not applicable; NR, examined but not reported.

${ }^{a}$ Studies are excluded at the moderating factor analyses. Only the van der Vlies et $\mathrm{al}^{45} 2012$ study reported the percentage of medicated patients with $\mathrm{AD}$

${ }^{\mathrm{b}}$ Two different techniques were used with the same cohort.

\begin{tabular}{|c|c|c|c|c|}
\hline Variables & Slope & SE & $P$ Value & No. \\
\hline Quality (STROBE) & 0.0545 & 0.1184 & .6455 & 15 \\
\hline Field strength & 0.3924 & 0.1482 & .0081 & 15 \\
\hline Male (\%) & -0.0085 & 0.0260 & .7449 & 12 \\
\hline Age AD (mean, yr) & 0.0484 & 0.0456 & .2881 & 12 \\
\hline MMSE (mean score) & -0.1919 & 0.1119 & .0864 & 9 \\
\hline Apoe- $\epsilon 4$ (\%) & 0.0117 & 0.0091 & .1992 & 5 \\
\hline No. of image raters & 0.1330 & 0.1598 & .4055 & 12 \\
\hline \multicolumn{5}{|l|}{ Postupdate ${ }^{\mathrm{a}}$} \\
\hline Year of publication & 0.1099 & 0.0518 & .0340 & 16 \\
\hline
\end{tabular}

Note:-SE indicates standard error; MMSE, Mini-Mental State Examination; No., number of outcomes included in the analysis; imaging technique: TE and TR.

${ }^{a}$ No statistical change was observed for all other variables in the Table after analyzing with the new study.

tive analyses for publication bias were nonsignificant $(P>.05)$, suggesting a lack of significant bias.

Global/diffuse distribution of the MB event rate was similar to the global effect $(\mathrm{ER}=0.24, n=11)$; and for cortical, subcortical, or nonspecified MB locations, various prevalence rates were reported. For those that reported explicitly and used a size of $\leq 10 \mathrm{~mm}$ to define MBs, the prevalence of MBs was 25 $(\mathrm{ER}=0.25, n=13)$.

\section{Moderating Factors}

Imaging Techniques. With SWI (ER $=0.40, n=5)$, the prevalence was more than twice as high as that in those studies conducted with GRE imaging $(\mathrm{ER}=0.18, n=7)$ or EPI $(\mathrm{ER}=$ $0.19, n=3)$. For Siemens scanners, the prevalence of MB was $27 \%$ $(\mathrm{ER}=0.27, n=8)$.

Demographics. Age $(P=.29)$, sex $(P=.75)$, and global cognition $(P=.09)$ assessed by single mixed-effects meta-regression did not modify the prevalence of MBs (Table 2). For cigarette smoking, the prevalence of MBs was nearly 25\% (ER = 0.246; 95\% CI, 0.200-0.298). Details for medication and substance use were insufficient for further analyses.
Diagnostic Characteristics. For studies reporting explicitly on probable $\mathrm{AD}$ as per the diagnostic framework of McKhann et al, ${ }^{23}$ the prevalence of $\mathrm{MBs}(\mathrm{ER}=0.27, n=7)$ was slightly higher compared with those studies that did not specify an AD diagnostic criterion ( $\mathrm{ER}=0.24, n=6$ ) but was significantly higher than those reporting a combination of probable and possible $\mathrm{AD}$ groups $(\mathrm{ER}=0.14, n=2)$. The associations between MBs and age, sex, and global cognitive status were not significant factors that affected the prevalence of MBs for probable $\mathrm{AD}(P>.1)$.

Quality Assessment. The quality of studies as assessed by STROBE guidelines did not appear to affect the overall event rate estimate (slope $=0.055$, standard error $=0.118, P=.646$, $n=15)$.

Details on event rates and meta-regression results are listed in Table 2 and On-line Table 3.

\section{Heterogeneity}

The heterogeneity was assessed by using multivariable meta-regressions. For the imaging model, independently, the field strength was significant $(P<.002)$ and explained approximately $34 \%$ of the between-study variability but was no longer significant when the scanner type and, subsequently, the technique were included in the model. When including the field strength and scanner type, GRE explained $73 \%$ and SWI explained $93 \%$ of the variability. When all 3 variables were included in the model, only the Philips scanner was significant. This effect was not present when initially the technique and then the scanner type were entered into the model.

None of the other models (demographic, clinical factors, lacunae/stroke/hemorrhage) and clinical $\mathrm{AD}$ diagnoses (probable/ probable-possible/not specified) and none of the risk factors (apolipoprotein E4 carriers, hypertension), alone or in combination, were statistically significant or resulted in a between-study variability of $>3 \%$. Immunotherapy and antiplatelet therapy were not examined due to limited data. 


\section{Prevalence of Other Dementias}

Within the subset of studies that provided a comparison group, the presence of MBs in vascular dementia was 58\% (71 of 122 cases of vascular dementia, 4 studies), 16\% for healthy controls or the subjective cognitive impairment group (92 of 553 cases of controls, 7 studies), 28\% for mild cognitive impairment (105 of 376 cases of MCI, 7 studies), and 14\% for a group containing mixed diagnoses (eg, including $\mathrm{AD}$, vascular dementia, mixed dementia) (50 of 358 cases of mixed diagnosis, 6 studies). Analyses comparing the prevalence of $\mathrm{MBs}$ in $\mathrm{AD}$ with frontotemporal lobar dementia and Lewy body dementia were not possible, given that only 1 study ${ }^{24}$ made these comparisons. The ORs for these comparisons are given in On-line Fig 1.

\section{Risk Factors}

The MB prevalence rate for the studies reporting the percentage of apolipoprotein E4 carriers (heterozygote, homozygote, or both) was similar to the global aggregate (On-line Table 3 ). The effect of the percentage of apolipoprotein E4 carriers on the prevalence rate via single meta-regression was nonsignificant (Table 2). There was no effect of hypertension on the prevalence of MBs (slope = 0.015 , standard error $=0.042, P=.71$ ).

\section{Literature Update}

Update of the literature review, based on screening, yielded 3 studies. Two of the 3 studies were excluded, ${ }^{25,26}$ and the only study meeting our selection criteria ${ }^{27}$ was added to the remaining of studies. To avoid investigator bias, we also performed analyses of the added new article separately. Small changes were observed in the global prevalence of MBs (24.9\% versus $24.1 \%)$ and other variables, which are listed in Table 2 and On-line Table 3. On-line Fig 2 shows the forest plot for the updated aggregate event rate.

\section{Effect of Publication Year}

Single-variable meta-regression analysis to examine the effect of publication year on the $\mathrm{MB}$ prevalence rates was significant $(P=$ $.034)$.

\section{DISCUSSION}

The aggregate $\mathrm{MB}$ prevalence emerging from this meta-analysis for patients with $\mathrm{AD}$ was $24 \%$, and $25 \%$ after including an additional study that emerged from a search update in May 2015, and was similar to the earlier findings from studies reported by Cordonnier and van der Flier (23\%). ${ }^{3}$ Apparent prevalence is particularly affected by the image-acquisition technique (GRE, EPI, SWI). Those studies applying SWI had twice the prevalence rates for MBs as studies using GRE or EPI. SWI is highly sensitive to susceptibility-related contrast because of combining phase and magnitude images. In studies of neurotrauma, SWI was found to detect up to 5 times as many hemorrhages compared with GRE. ${ }^{28}$ However, SWI requires appropriate reconstruction of data acquired with multichannel coils. If the data from the individual channels are combined incorrectly, the phase images may exhibit singularities that lead to artifactual MBs in the final SWI. ${ }^{22}$ These singularities are avoided if complex valued coil sensitivity maps are used for the channel combination (sensitivity encoding reconstruction). ${ }^{10,22,29}$ On some scanner platforms, the correct coil combination is implemented by default, ${ }^{10}$ whereas on other platforms, it must be implemented by the end user. ${ }^{4,29}$

Patients with AD have increased prevalence rates of MBs compared with healthy controls and those with subjective cognitive impairment. Our aggregate prevalence of MBs for AD was considerably higher than that reported in the literature for asymptomatic or healthy elderly individuals ( 11.1 versus $25 \%),{ }^{30}$ and it is consistent with the literature reporting higher prevalence in atypical $\mathrm{AD}$ compared with $\mathrm{AD} .^{31}$

The prevalence of MBs from studies reporting explicitly on probable $\mathrm{AD}$ was higher than that in those reporting a combination of probable and possible $\mathrm{AD}(14 \%$ versus $27 \%)$. This is potentially because in the latter group, the balance in the number of patients included between possible and probable $\mathrm{AD}$ was not clear and the pathology could have been frontotemporal lobar dementia or Lewy body dementia-like, which are expected to have lower prevalences of MBs.

The current results have implications for disease monitoring and imaging outcomes in drug development. SWI would show more bleeds at baseline and would be more sensitive to detecting new MBs, which may have implications for safety monitoring in phase II trials. Also, a change in the MB number and size could be associated with the severity of primary pathology and secondary symptoms.

Whether an increase in $\mathrm{MB}$ detection translates into a clinically meaningful difference remains debatable. ${ }^{22} \mathrm{MBs}$ contribute to the pathophysiology of the illness, and they potentially indicate a link between amyloid pathology and neurovascular change. ${ }^{3,32}$ Moreover, the presence of MBs and the overall MB burden have prognostic significance for $\mathrm{AD}^{33-35}$ and may affect cognition. ${ }^{8,36}$ Better imaging of the $\mathrm{MBs}$ in $\mathrm{AD}$ may allow better understanding of the pathophysiology of MBs in $\mathrm{AD}$ and the role that smallvessel disease plays in $\mathrm{AD}$ pathology.

The strength of our study is that we examined multiple moderating variables that to date, no other study has performed, to our knowledge. Scanner type (Siemens and GE Healthcare), use of SWI technique, field strength, and diagnosis of probable $\mathrm{AD}$ and $\mathrm{MB}$ definition $(\leq 10 \mathrm{~mm}$ ) were factors that increased the prevalence over the global aggregate. We also found that great variability existed as a function of $\mathrm{AD}$ diagnosis, but not because of age, sex, or cognitive status.

Our meta-analysis has certain limitations. Given the requirement for multiple single-variable meta-regression analysis, an increased probability of type I error exists. However, the results remain unchanged when examined at a significance level of $P=$ .01 . Additionally, multivariable meta-regressions were used to investigate heterogeneity without dropping studies that would have been limitations in other approaches. Nonetheless, the limited number of studies and some missing data, which preclude sufficient analyses of publication bias and multivariable modeling, suggest that some results should be considered with caution.

Most of the studies included in our analyses did not explicitly state that patients with a history of brain injury, stroke, or other sources of hemorrhage were excluded. Because these events can result in localized regions of tissue damage that could be misconstrued as AD-associated MBs instead of injury-associated MBs by raters, there is a risk that inclusion of patients with head injury, 
neurovascular pathology, or hemorrhage would have skewed their reported results. Additionally, we were unable to contact the authors for missing data, which would have added power to each component of the analyses, specifically at the meta-regression level.

Because of a paucity of detailed data on patients' medication regimens, we could not determine the effect of immunotherapy on the rate of MBs. Certain types of $\mathrm{A} \beta$-42-based immunotherapy are hypothesized to aggravate cerebral amyloid angiopathy-related vascular damage or dysfunction. ${ }^{37,38}$ We found no significant effect of the presence of the apolipoprotein E4 allele on the prevalence of MBs. This lack of effect could be due to heterogeneity in reporting the status of the apolipoprotein $E 4$ allele carriers (heterozygote, homozygote, or both). In fact, some studies reported the percentage of the carrier without specifying allele variants, whereas others reported exact rates for homozygotes and or heterozygotes.

\section{Future Directions}

Future studies examining the prevalence of MBs in $\mathrm{AD}$ should report the number, size, and location of MBs more precisely, which may allow analysis of the relationship between these factors and neurocognitive outcomes. Given the large differences in prevalence among different imaging technologies, future studies should attempt to use technologies that can be standardized and are sensitive, yet widely available. SWI with 3T scanners is now emerging as the standard for identifying MBs. This is consistent with our finding that the year of publication is positively correlated with the prevalence of MBs. In addition, MR imaging scanner manufacturers need to ensure that artifact-free SWI is provided. Field strengths of 7T and above are gaining importance in research and may eventually be used in clinical settings, which may result in a further increase in the prevalence of MBs in patients imaged on such systems. ${ }^{39}$

\section{CONCLUSIONS}

Imaging technique and field strength are strongly associated with the prevalence of microbleeds over the global aggregate. Standardized imaging protocols for identification of microbleeds are recommended to minimize confounds.

\section{ACKNOWLEDGMENTS}

We thank Charlotte Beck (University of British Columbia medical librarian) for assisting with the search methodology.

Disclosures: Ging-Yuek Hsiung-UNRELATED: Grants/Grants Pending: Canadian Institutes of Health Research, ${ }^{*}$ Brain Canada, ${ }^{*}$ National Institutes of Health/National Institute on Aging, , Heart and Stroke Foundation, ${ }^{*}$ Hoffmann-La Roche,* TauRx, ${ }^{*}$ AstraZeneca, ${ }^{*}$ Eli Lilly, ${ }^{*}$ and Genentech, ${ }^{*}$ Comments: I have received grants from the Canadian Institutes of Health Research, Brain Canada, the National Institutes of Health/National Institute on Aging, and the Heart and Stroke Foundation of Canada for academic research projects. I have also received funds from sponsors for conduction of clinical trials, including Hoffmann-La Roche, TauRx, AstraZeneca, Eli Lilly, and Genentech. Alexander Rauscher-UNRELATED: Board Membership: Hoffmann-La Roche. Drs Sepehry and Lang have no financial interest or conflict of interest to report. *Money paid to the institution.

\section{REFERENCES}

1. Gorelick PB, Scuteri A, Black SE, et al; American Heart Association Stroke Council, Council on Epidemiology and Prevention, Council on Cardiovascular Nursing, Council on Cardiovascular Radiology and Intervention, and Council on Cardiovascular Surgery and Anesthesia. Vascular contributions to cognitive impairment and dementia: a statement for healthcare professionals from the American Heart Association/American Stroke Association. Stroke 2011; 42:2672-713 CrossRef Medline

2. Heringa SM, Reijmer YD, Leemans A, et al; Utrecht Vascular Cognitive Impairment (VCI) Study Group. Multiple microbleeds are related to cerebral network disruptions in patients with early Alzheimer's disease. J Alzheimers Dis 2014;38:211-21 CrossRef Medline

3. Cordonnier C, van der Flier WM. Brain microbleeds and Alzheimer's disease: innocent observation or key player? Brain 2011;134: 335-44 CrossRef Medline

4. Kirsch W, McAuley G, Holshouser B, et al. Serial susceptibility weighted MRI measures brain iron and microbleeds in dementia. J Alzheimers Dis 2009;17:599-609 CrossRef Medline

5. Hommet C, Mondon K, Constans T, et al. Review of cerebral microangiopathy and Alzheimer's disease: relation between white matter hyperintensities and microbleeds. Dement Geriatr Cogn Disord 2011;32:367-78 CrossRef Medline

6. van der Flier WM. Clinical aspects of microbleeds in Alzheimer's disease. J Neurol Sci 2012;322:56-58 CrossRef Medline

7. Cordonnier C, van der Flier WM, Sluimer JD, et al. Prevalence and severity of microbleeds in a memory clinic setting. Neurology 2006; 66:1356-60 CrossRef Medline

8. Goos JD, Kester MI, Barkhof F, et al. Patients with Alzheimer disease with multiple microbleeds: relation with cerebrospinal fluid biomarkers and cognition. Stroke 2009;40:3455-60 CrossRef Medline

9. Frisoni GB, Fox NC, Jack CR Jr, et al. The clinical use of structural MRI in Alzheimer disease. Nat Rev Neurol 2010;6:67-77 CrossRef Medline

10. Denk C, Rauscher A. Susceptibility weighted imaging with multiple echoes. J Magn Reson Imaging 2010;31:185-91 CrossRef Medline

11. Haacke EM, Xu Y, Cheng YC, et al. Susceptibility weighted imaging (SWI). Magn Reson Med 2004;52:612-18 CrossRef Medline

12. Borenstein M, Hedges L, Higgins J, et al. Comprehensive Meta-Analysis. 2nd ed. Englewood, New Jersey: Biostat; 2005

13. Johnson BT. DSTAT: Software for the Meta-Analytic Review of Research Literatures. Version 1. Hillsdale, New Jersey: Lawrence Erlbaum Associates; 1993

14. von Elm E, Altman DG, Egger M, et al; STROBE Initiative. The Strengthening the Reporting of Observational Studies in Epidemiology (STROBE) statement: guidelines for reporting observational studies. Epidemiology 2007;18:800-04 CrossRef Medline

15. Stroup DF, Berlin JA, Morton SC, et al. Meta-analysis of observational studies in epidemiology: a proposal for reporting-Metaanalysis Of Observational Studies in Epidemiology (MOOSE) group. JAMA 2000;283:2008-12 CrossRef Medline

16. Moher D, Liberati A, Tetzlaff J, et al; PRISMA Group. Preferred reporting items for systematic reviews and meta-analyses: the PRISMA statement. Int J Surg 2010;8:336-41 CrossRef Medline

17. Begg CB, Mazumdar M. Operating characteristics of a rank correlation test for publication bias. Biometrics 1994;50:1088-101 CrossRef Medline

18. Egger M, Davey Smith G, Schneider M, et al. Bias in meta-analysis detected by a simple, graphical test. BMJ 1997;315:629-34 CrossRef Medline

19. Higgins JP, Thompson SG, Deeks JJ, et al. Measuring inconsistency in meta-analyses. BMJ 2003;327:557-60 CrossRef Medline

20. Nagasawa J, Kiyozaka T, Ikeda K. Prevalence and clinicoradiological analyses of patients with Alzheimer disease coexisting multiple microbleeds. J Stroke Cerebrovasc Dis 2014;23:2444-49 CrossRef Medline

21. Fukui T, Oowan Y, Yamazaki T, et al. Prevalence and clinical implication of microbleeds in dementia with Lewy bodies in comparison with microbleeds in Alzheimer's disease. Dement Geriatr Cogn Dis Extra 2013;3:148-60 CrossRef Medline 
22. Goos JD, van der Flier WM, Knol DL, et al. Clinical relevance of improved microbleed detection by susceptibility-weighted magnetic resonance imaging. Stroke 2011;42:1894-900 CrossRef Medline

23. McKhann G, Drachman D, Folstein M, et al. Clinical diagnosis of Alzheimer's disease: report of the NINCDS-ADRDA Work Group under the auspices of Department of Health and Human Services Task Force on Alzheimer's Disease. Neurology 1984;34:939-44 CrossRef Medline

24. Uetani H, Hirai T, Hashimoto M, et al. Prevalence and topography of small hypointense foci suggesting microbleeds on $3 \mathrm{~T}$ susceptibility-weighted imaging in various types of dementia. AJNR Am J Neuroradiol 2013;34:984-89 CrossRef Medline

25. Shams S, Martola J, Granberg T, et al. Cerebral microbleeds: different prevalence, topography, and risk factors depending on dementia diagnosis - the Karolinska Imaging Dementia Study. AJNR Am J Neuroradiol 2015;36:661-66 CrossRef Medline

26. Shams S, Martola J, Cavallin L, et al. SWI or T2*: Which MRI sequence to use in the detection of cerebral microbleeds? The Karolinska Imaging Dementia Study. AJNR Am J Neuroradiol 2015;36: 1089-95 CrossRef Medline

27. Olazarán J, Ramos A, Boyano I, et al. Pattern of and risk factors for brain microbleeds in neurodegenerative dementia. Am J Alzheimers Dis Other Demen 2014;29:263-69 CrossRef Medline

28. Benedictus MR, Goos JDC, Binnewijzend MA, et al. Specific risk factors for microbleeds and white matter hyperintensities in Alzheimer's disease. Neurobiol Aging 2013;34:2488-94 CrossRef Medline

29. Kester MI, Goos JD, Teunissen CE, et al. Associations between cerebral small-vessel disease and Alzheimer disease pathology as measured by cerebrospinal fluid biomarkers. JAMA Neurol 2014;71: 855-62 CrossRef Medline

30. Cordonnier C. Brain microbleeds: more evidence, but still a clinical dilemma. Curr Opin Neurol 2011;24:69-74 CrossRef Medline

31. Whitwell JL, Kantarci K, Weigand SD, et al. Microbleeds in atypical presentations of Alzheimer's disease: a comparison to dementia of the Alzheimer's type. J Alzheimers Dis 2015;45:1109-17 CrossRef Medline

32. Staekenborg SS, Koedam ELGE, Henneman WJP, et al. Progression of Mild Cognitive Impairment to Dementia Contribution of Cerebrovascular Disease Compared with Medial Temporal Lobe Atrophy. 4th ed. Philadelphia: Lippincott Williams and Wilkins; 2009:1269-74

33. Martinez-Ramirez S, Greenberg SM, Viswanathan A. Cerebral microbleeds: overview and implications in cognitive impairment. Alzheimers Res Ther 2014;6:33 CrossRef Medline

34. Poels MM, Ikram MA, van der Lugt A, et al. Cerebral microbleeds are associated with worse cognitive function: the Rotterdam Scan Study. Neurology 2012;78:326-33 CrossRef Medline

35. van Norden AG, van Uden IW, de Laat KF, et al. Cognitive function in small vessel disease: the additional value of diffusion tensor imaging to conventional magnetic resonance imaging: the RUN DMC study. J Alzheimers Dis 2012;32:667-76 CrossRef Medline

36. Pettersen JA, Sathiyamoorthy G, Gao FQ, et al. Microbleed topography, leukoaraiosis, and cognition in probable Alzheimer disease from the Sunnybrook dementia study. Arch Neurol 2008;65:790-95 CrossRef Medline

37. Sperling R, Salloway S, Brooks DJ, et al. Amyloid-related imaging abnormalities in patients with Alzheimer's disease treated with bapineuzumab: a retrospective analysis. Lancet Neurol 2012;11: 241-49 CrossRef Medline

38. Werring DJ, Sperling R. Inflammatory cerebral amyloid angiopathy and amyloid-modifying therapies: variations on the same ARIA? Ann Neurol 2013;73:439-41 CrossRef Medline

39. Brundel M, Heringa SM, de Bresser J, et al. High prevalence of cerebral microbleeds at 7Tesla MRI in patients with early Alzheimer's disease. J Alzheimers Dis 2012;31:259-63 CrossRef Medline
40. Nagata K, Takano D, Yamazaki T, et al. Cerebrovascular lesions in elderly Japanese patients with Alzheimer's disease. J Neurol Sci 2012;322:87-91 CrossRef Medline

41. Nakata-Kudo Y, Mizuno T, Yamada K, et al. Microbleeds in Alzheimer disease are more related to cerebral amyloid angiopathy than cerebrovascular disease. Dement Geriatr Cogn Disord 2006;22:8-14 CrossRef Medline

42. Park JH, Seo SW, Kim C, et al. Pathogenesis of cerebral microbleeds: in vivo imaging of amyloid and subcortical ischemic small vessel disease in 226 individuals with cognitive impairment. Ann Neurol 2013;73:584-93 CrossRef Medline

43. Qiu C, Cotch MF, Sigurdsson S, et al. Cerebral microbleeds, retinopathy, and dementia: the AGES-Reykjavik Study. Neurology 2010;75: 2221-28 CrossRef Medline

44. Staekenborg SS, Koedam EL, Henneman WJ, et al. Progression of mild cognitive impairment to dementia: contribution of cerebrovascular disease compared with medial temporal lobe atrophy. Stroke 2009;40:1269-74 CrossRef Medline

45. van der Vlies AE, Goos JD, Barkhof F, et al. Microbleeds do not affect rate of cognitive decline in Alzheimer disease. Neurology 2012;79: 763-69 CrossRef Medline

46. Yates PA, Desmond PM, Phal PM, et al. Incidence of cerebral microbleeds in preclinical Alzheimer disease. Neurology 2014;82: 1266-73 CrossRef Medline

47. Zonneveld HI, Goos JD, Wattjes MP, et al. Prevalence of cortical superficial siderosis in a memory clinic population. Neurology 2014; 82:698-704 CrossRef Medline

48. Atri A, Locascio JJ, Lin JM, et al. Prevalence and effects of lobar microhemorrhages in early-stage dementia. Neurodegener Dis 2005; 2:305-12 CrossRef Medline

49. Gurol ME, Viswanathan A, Gidicsin C, et al. Cerebral amyloid angiopathy burden associated with leukoaraiosis: a positron emission tomography/magnetic resonance imaging study. Ann Neurol 2013; 73:529-36 CrossRef Medline

50. Danve A, Grafe M, Deodhar A. Amyloid beta-related angiitis: a case report and comprehensive review of literature of 94 cases. Semin Arthritis Rheum 2014;44:86-92 CrossRef Medline

51. Ghostine S, Raghavan R, Khanlou N, et al. Cerebral amyloid angiopathy: micro-haemorrhages demonstrated by magnetic resonance susceptibility-weighted imaging. Neuropathol Appl Neurobiol 2009;35:116-19 CrossRef Medline

52. Henneman WJ, Sluimer JD, Cordonnier C, et al. MRI biomarkers of vascular damage and atrophy predicting mortality in a memory clinic population. Stroke 2009;40:492-98 CrossRef Medline

53. Hilal S, Saini M, Tan CS, et al. Ankle-brachial index, cognitive impairment and cerebrovascular disease in a Chinese population. Neuroepidemiology 2014;42:131-38 CrossRef Medline

54. Kimberly WT, Gilson A, Rost NS, et al. Silent ischemic infarcts are associated with hemorrhage burden in cerebral amyloid angiopathy. Neurology 2009;72:1230-35 CrossRef Medline

55. Ku HL, Chi NF. Cerebral lobar microhemorrhages detection by high magnetic field susceptibility weighted image: a potential diagnostic neuroimage technique of Alzheimer's disease. Med Hypotheses 2011;76:840-42 CrossRef Medline

56. Kuijf HJ, Brundel M, de Bresser J, et al. Semi-automated detection of cerebral microbleeds on 3.0 T MR images. PLoS One 2013;8:e66610 CrossRef Medline

57. Ii $\mathrm{Y}$, Maeda M, Kida $\mathrm{H}$, et al. In vivo detection of cortical microinfarcts on ultrahigh-field MRI. J Neuroimaging 2013;23:28-32 CrossRef Medline

58. van Assema DM, Goos JD, van der Flier WM, et al. No evidence for additional blood-brain barrier P-glycoprotein dysfunction in Alzheimer's disease patients with microbleeds. J Cereb Blood Flow Metab 2012;32:1468-71 CrossRef Medline

59. Van Rooden S, Goos JD, van Opstal AM, et al. Increased number of microinfarcts in Alzheimer disease at 7-T MR imaging. Radiology 2014;270:205-11 CrossRef Medline

60. van Veluw SJ, Heringa SM, Kuijf HJ, et al. Cerebral cortical micro- 
infarcts at 7Tesla MRI in patients with early Alzheimer's disease. $J$ Alzheimers Dis 2014;39:163-67 CrossRef Medline

61. Vidal JS, Sigurdsson S, Jonsdottir MK, et al. Coronary artery calcium, brain function and structure: the AGES-Reykjavik Study. Stroke 2010;41:891-97 CrossRef Medline

62. Wollenweber FA, Buerger K, Mueller C, et al. Prevalence of cortical superficial siderosis in patients with cognitive impairment. J Neurol 2014;261:277-82 CrossRef Medline
63. Yates PA, Sirisriro R, Villemagne VL, et al; AIBL Research Group. Cerebral microhemorrhage and brain $\boldsymbol{\beta}$-amyloid in aging and Alzheimer disease. Neurology 2011;77:48 -54 CrossRef Medline

64. Yokoyama S, Kajiya Y, Yoshinaga T, et al. Imaging discrepancies between magnetic resonance imaging and brain perfusion singlephoton emission computed tomography in the diagnosis of Alzheimer's disease, and verification with amyloid positron emission tomography. Psychogeriatrics 2014;14:110-17 CrossRef Medline 